\title{
Taking stock of mangrove and seagrass blue carbon ecosystems: A perspective for future carbon trading
}

\author{
John Barry Gallagher \\ Borneo Marine Research Institute, Universiti Malaysia Sabah, 88400 Kota Kinabalu, Sabah, Malaysia \\ Corresponding author: john.barry@ums.edu.my
}

\begin{abstract}
Seagrass and mangroves support a number of ecosystem services, such as sustaining marine fisheries, water clarity, and the protection of shoreline from erosion. Producing a national and global consensus of their total worth is a challenge. More often than not the variety and distal evaluation approaches do not fit comfortably within current market-based economic models, which are arguably more capable of swaying government policy in assessing their preservation over economic development. The exception to this rule is the increasing recognition of the importance of these systems as a carbon sink for combating 'greenhouse' gas emissions. In response, these sinks have been labelled as 'Blue Carbon, a rhetorical tool to distinguish them from terrestrial and ocean sinks, and the different approaches they would require for conservation. However, there are a number of knowledge gaps, untested underlying assumptions, and measurement practicalities in assessing an accurate value of carbon sequestration and storage. Unless these are addressed, then the push for seagrass and mangroves to be included within the carbon-financing network may not be successful. This short communication discusses the limitations of the current blue carbon conceptual model, and provides recommendations for a more limited but robust submission of its present and future worth, required for carbon financing.
\end{abstract}

Keywords: Blue carbon, Carbon sequestration, Mangrove, Seagrass, Carbon financing

\section{Introduction}

Human activities appear responsible for changing the global climate through anthropogenic emissions of $\mathrm{CO}_{2}$ and other greenhouse gases (Gray, 2007; Nellemann et al., 2009; Anderegg et al., 2010; IPCC, 2013). This realisation has highlighted the importance of conserving existing carbon sinks not only on land, but also along vegetated subtidal and intertidal coastal strips. These coastal areas are now referred to as 'Blue Carbon' ecosystems (Nellemann et al., 2009), and have been estimated to contribute around $50 \%$ of the marine environment's total carbon sequestration (Duarte et al., 2005). Unfortunately, coastal developments continue to severely degrade these systems. Estimates put the release of carbon dioxide from coastal vegetated loss between 0.15-1.02 billion tons annually, causing \$US 6-42 billion annually in economic damage (Pendleton et al., 2012). Estimates such as these have begun to focus the attention of the global climate change community - like the United Nations Framework Convention on Climate Change (UNFCC), Manado Ocean Declaration (2009), Cancú Agreement (2010) and the Rio Ocean Declaration (2012), to the use of carbon credits as source of income for users and custodians of these environments as an important component in the mitigation of climate change. However, the bias towards terrestrial carbon sinks has until now excluded blue carbon within current regulatory compliance or voluntary carbon markets. Nevertheless, advocacy for their inclusion continues (Hejnowicz et al. (2015), based on an implicit certainty in the blue carbon conceptual model, ease of measurement and carbon service evaluation over climatic scales; I contend not from their importance at the global scale but on a case-bycase arguably a requirement by any market trading scheme which deals with tangible and measureable products based on a science that has certainty.

The aim of this communication is to provide a perspective designed to stimulate a discussion on the current state, assumptions, and limitations of the blue carbon model and measurements required to assess the value of their carbon sinks. The article focuses on mangrove and seagrasses. The assembled insights are then used to suggest what practical and pragmatic measures, exclusions, and projections are likely to be required for inclusion in a carbon market scheme.

\section{The blue carbon model}

The current blue carbon conceptual model is a description of autotrophic and allochthonous inputs and losses of organic carbon. The model's inputs and losses also define what components can be counted as a carbon storage service, although not in isolation, but relative to the storage gains produced by a replacement ecosystem or coastal development. Interestingly, this definition would not necessarily preclude oligotrophic vegetated or estuarine mud ecosystems, which can be characteristically heterotrophic (Duarte and Agusti, 1998; Cebrian et al., 1998). Of course, producing a bottom-up carbon sequestration balance, which measures all the components within the model, will give important ecological insights. However, a carbon financing scheme requires only two estimates, namely, the ecosystem's 
carbon sequestration rates and the size of carbon sink that is vulnerable to disturbance. What measurements are required to best estimate the extent of the above two services can be understood by deconstructing the processes and inputs as a series of balanced equations (Equations 1 to 3):

$$
\begin{aligned}
& N E P=G p-C r \\
& C r=P r+D r+S r+H r \\
& N E S=N E P+I-I r-E=S
\end{aligned}
$$

Equation 1

Equation 2

Equation 3

Where, NEP is the net autotrophic ecosystem productivity. This input is the balance between the gross primary productivity of the macro/micro plant assemblage $(G p)$ and its respiratory consumption $(\mathrm{Cr})$. The $\mathrm{Cr}$, being the sum respiration from plant assemblage $(\mathrm{Pr})$, detritivore $(\mathrm{Dr})$, sedimentary microfloral $(\mathrm{Sr})$, and herbivores $(\mathrm{Hr})$. The architecture of the canopy and root system also provides a service by trapping allochthonous organic detritus $(I)$ from adjacent environs, and in part, preserving after some of that has been respired (Ir). As this organic material would have otherwise been completely mineralised outside the ecosystem (Cathalot et al., 2013), it represents the other input. The net ecosystem sequestration then becomes the balance between those inputs and the loss and subsequent complete mineralisation of the ecosystem's litter (Duarte et al., 2005). Mangroves and seagrasses still manage to export around $30 \%$ and $24 \%$ of their NPP as leaf litter (Duarte and Cebrián, 1996), and excrete $35 \%$ as dissolved organic carbon (DOC) (Krause-Jensen and Duarte, 2016; Duarte and KrauseJensen, 2017). In this way, sequestration rates can be measured directly from the rates of organic carbon burial $(S$, Equation 3) of the recalcitrant organic matter that is assumed to remain after one or two years of deposition (Cebrian, 1999). Given the above two vectors, carbon markets would then only require a sufficiently large number of stock measurements over different scales to capture the spatial and temporal variability across the ecosystem's landscape/seascape unit (Habeeb et al., 2007; Yamakita et al., 2010) (Nellemann et al., 2009), and a smaller number of sedimentary sequestration measurements to a depth that captures the temporal variability over climatic scales from the late Anthropocene (Breithaupt et al., 2012). However, an estimate of the likely depth of disturbance down the sediment by future events or developments (Siikamäki et al., 2013) is more problematical for a case by case basis. Nevertheless, by applying the concept 'likely replacement' for different types of disturbances within that area, a pragmatic solution may be found. For example, nearby natural bare wetland and coastal sediments (Gullström et al., 2017) are useful proxies for the loss of the seagrass canopy from eutrophication, sediment resuspension due to port activities or aquaculture (Gallagher, 2015), as well as mature disturbance regimes where mangroves had been logged or replaced with aquaculture ponds over a generation ago (Siikamäki et al., 2013). In time a set of disturbance coefficients, and their variance, may be calculated, in much the same way as used to estimate and mange catchment nutrient and sediment loading to estuaries and lagoons (National Research Council, 2000).

All the above requirements, while challenging, appear to be plausible, pending further research required to obtain correction coefficients for typical types of sedimentary disturbance. Such an approach is based on the tradition of broadly accepted land use catchment coefficients, used to estimate estuarine and lagoon nutrient loading across regions (National Research Council, 2000). The exception is in both the probably flawed means of calculating sedimentary carbon sequestration, and the philosophy behind its interpretation. Changes in rates of sedimentation over the late Anthropocene are commonly calculated with validated models of natural ${ }^{210} \mathrm{~Pb}$ profiles (Carroll et al., 1995; Smith, 2001; Appleby, 2008). Researchers then use this accretion rate with the organic carbon content to calculate their rates of sequestration. Gallagher $(2014,2015)$, however, pointed out that the current 2-box sediment mineralisation model of Cebrian (1999) is outdated. A more realistic and universally robust model is one in which organic carbon becomes continuously recalcitrant. Here, the rate of temporal change in decay constant appears to be universal, from which the only starting apparent age is required for decay predictions, and accessible from the surface organic carbon profile (Middelburg, 1989; Burdige, 2007). Consequently, Gallagher (2015) suggested that the sequestration rate will need to be referenced to carbon concentration after a period of decay that encompasses climatic variability, as the sum of negative and positive phases of the Pacific Decadal Oscillation, Monsoons and North Atlantic Oscillation (around 80 years) (Stenseth et al., 2003). However, using the newly calculated sequestration's mean and variability implicitly assumes that past 80-year sequestration variability will also be a measure of a future 80-year variability. Can the past predict the future? The answer is probably, but at small decadal scales when the solution becomes a time series analysis, a statistical method familiar to trading markets. I recommend the use of Singular Spectrum Analysis. This imputation technique is ideal for irregular short time series, in which projections may be updated relatively easily (Kondrashov and Ghil, 2006; Gallagher, 2013).

It should also be noted that the interdecadal variability in climate, which affects change in upwelling and river flows, is also associated with variability in seagrass and kelp coastal productivity and biomass (Marba and Duarte, 1997; Dayton et al., 1999; Martin et al., 2010; Gallagher, 2011). This would appear to violate steady state assumptions within the blue carbon model. Consequently, updates would also need to account for changes in seagrass coverage, sequestration, and stocks that were not accounted for at the time of the audit, together with any recovery of immature mangrove forest previous lost or replanted. 


\section{Limitation of the blue carbon conceptual model}

Blue carbon sequestration and stock measurements, and the services they can provide on a case-by-case basis, appear to be solvable within the construct of the conceptual model. However, recent insights have challenged the narrow selection of input variables and storage boundary conditions. The consequence, may both weaken and strengthen the blue carbon ecosystem's ability to mitigate the effects of climate change, as well as introducing a potential new type of service, namely, a buffer capacity that constrains the evasion of carbon dioxide from the water body after disturbance. It would appear, that sequestration rates can be offset by the net sequestration of calcium carbonate (Equation 4) from epibionts, molluscs and bivalves, as a net source of carbon dioxide to shallow waters and the atmosphere (Burdige and Zimmerman, 2002; Hu and Burdige, 2008; Mazarrasa et al., 2015; Howard et al., 2017).

$\mathrm{Ca}^{2+}+2 \mathrm{HCO}^{3-}=\mathrm{CaCO}_{3}+\mathrm{H}_{2} \mathrm{O}+\mathrm{CO}_{2}$

Equation 4

However, it should also be noted that the calcium carbonate dissolution will also take up carbon dioxide (see Equation 4), due to falls in $\mathrm{pH}$ during mineralisation of sedimentary organic carbon, accompanying oxidation from a disturbance. This results in what appears to be a reduction in the sequestration service during carbonate formation, but can be in part negated by its ability to buffer the evasion of carbon dioxide to the atmosphere after disturbance. The extent of this buffering service is unclear. Nevertheless, in a broad sense, it will decrease with flushing times (Howard et al., 2017), the dilution volume of the water body for subtidal seagrasses disturbances, and the rate of tidal exchange for intertidal seagrass mangrove disturbances. How this process can be incorporated into a carbon market is unclear other than applying appropriate coefficients based on carbonate stocks, dilution and volume, and tidal exchange in the manner of water body's susceptibility to eutrophication (National Research Council, 2000).

In addition to the issues of disturbance buffering capacity and sequestration offsets, recent insights have indicated that modifications of the value of the inputs and outputs of the model that also affect the effective carbon stocks need to be reassessed. Gallagher (2014) argued that a substantial fraction of macrophyte litter is not in fact respired but is exported and stored at the bottom of the nearby deep water submarine canyons. Furthermore, Gallagher (2014) suggested that there may be a substantial net storage component of the dissolved organic carbon (DOC) from the extensive macrophyte secretions (up to $35 \%$ of the NPP), as it is transformed into a more recalcitrant form within coastal waters (Hessen et al., 2004; Jiao et al., 2010). The above analysis has since then been extended to suggest more than $90 \%$ of macro-algal litter and $90 \%$ of DOC are exported to the deep sea, with a similar partitioning expected for seagrass (Krause-Jensen and Duarte, 2016; Duarte and Krause-Jensen, 2017). However, the science for DOC recalcitrant transformation is still within its embryonic stage, and seagrass litter export estimates on a case-by-case basis may be too challenging and uncertain to be presented to a carbon market. There will inevitably be issues and costs associated with oceanographic scales and the difficulty in assigning the source of litter to a particular seagrass meadow or mangrove forest.

Ultimately, I suggest, that the export of litter and DOC should be excluded as an additional storage component as a precautionary approach. The exclusion should not affect carbon market confidence, which arguably focusses on unexpected losses and not gains.

Finally, there are the more tangible organic carbon inputs, which when accounted for will reduce the sequestration mitigation service. These are the inputs of organic recalcitrants which are formed outside of blue carbon ecosystems. These forms, such as pyrogenic carbon from the incomplete combustion of biomass and fossil fuel, and possibly kerogens represent the major component of coastal sedimentary organic carbon (Cao et al., 2009; Luz et al., 2010; Coppola et al., 2014; Bird et al., 2015) and do not require the protection from mineralisation that burial affords (Gallagher, 2014). Consequently, any organic stocks and sequestration rates of these allochthonous recalcitrants should be measured, and subsequently excluded from the total organic carbon, currently used in stock and sequestration assessments.

\section{Conclusions}

Successful advocacy for blue carbon ecosystems requires certainty in the science and relative ease of accurately assessing the current and plausible sequestration rate and the extent of carbon stocks, which would otherwise be lost after a range of disturbances and coastal developments. Only then, these coastal ecosystems will be part of a regulatory and/or voluntary carbon trading/credit scheme. Such a scheme will be able to incentivise the users of these systems in their conservation and reap further benefits that these ecosystems provide. However, given the current state of the science and uncertainties in some export storage terms. I propose that sequestration assessment on a case by case basis should be restricted to measurements and time series projections of sedimentary organic accretion down their sediment columns, but after diagenetic correction to an age that accounts for climatic variability $(\sim 80$ year $)$. Furthermore, the contents of allochthonous recalcitrant forms, which cannot provide an additional blue carbon sequestration service, should be measured and subtracted from the diagenetically corrected total organic matter content. Stock estimates should be given to a depth of likely disturbance using local examples, bare sediment baselines and region coefficients. While accounting for the formation of carbon dioxide during calcium carbonate formation and deposition could be corrected, not at the time of sequestration but the expected net amount of carbon dioxide re-sequestered from carbonate dissolution after disturbance. Again, the efficiency estimated through the use of a series of coefficients that related tidal exchange, water flushing times and dilution within the system's water body. 


\section{References}

Anderegg, W.R.L., Prall, J.W., Harold, J. et al. (2010). Expert credibility in climate change. Proceedings of the National Academy of Sciences USA 107, 12107-12109.

Appleby, P.G. (2008). Three decades of dating recent sediments by fallout radionuclides: A review. Holocene 18, 83-93.

Bird, M.I., Wynn, J.G., Saiz, G. et al. (2015). The Pyrogenic Carbon Cycle. Annual Review of Earth \& Planetary Sciences 43, 273.

Breithaupt, J.L., Smoak, J.M., Smith, T.J. et al. (2012). Organic carbon burial rates in mangrove sediments: Strengthening the global budget. Global Biogeochemical Cycles 26.

Burdige, D.J. (2007). Preservation of organic matter in marine sediments: Controls, mechanisms, and an imbalance in sediment organic carbon budgets? Chemical Reviews 107, 467-485.

Burdige, D.J. \& Zimmerman, R.C. (2002). Impact of sea grass density on carbonate dissolution in Bahamian sediments. Limnology and Oceanography 47, 1751-1763.

Cao, Q., Chen, G. \& Miao, S. (2009). Distribution and correlations of polycyclic aromatic hydrocarbons with organic carbon and black carbon in surface sediments of three mangrove wetlands in the Shantou Wetland Demonstration Site, China. Acta Scientiae Circumstantiae 29, 861-868.

Carroll, J.L., Lerche, I., Abraham, J.D. et al. (1995). Model-determined sediment ages from $\mathrm{Pb}-210$ profiles in un-mixed sediments. Nuclear Geophysics 9, 553-565.

Cathalot, C., Rabouille, C., Tisnérat-Laborde, N. et al. (2013). The fate of river organic carbon in coastal areas: A study in the RhÔne River delta using multiple isotopic $(\delta 13 \mathrm{C}, \delta 14 \mathrm{C})$ and organic tracers. Geochimica et Cosmochimica Acta 118, 33-55.

Cebrian, J. (1999). Patterns in the fate of production in plant communities. The American Naturalist 154, 449-468.

Coppola, A.I., Ziolkowski, L.A., Masiello, C.A. et al. (2014). Aged black carbon in marine sediments and sinking particles. Geophysical Research Letters 41 2427-2433.

Dayton, P.K., Tegner, M.J., Edwards, P.B. et al. (1999). Temporal and spatial scales of kelp demography: The role of oceanographic climate. Ecological Monographs 69, 219-250.

Duarte, C.M. \& Cebrián, J. (1996). The fate of marine autotrophic production. Limnology and Oceanography 41, 1758-1766.

Duarte, C.M. \& Krause-Jensen, D. (2017). Export from Seagrass Meadows Contributes to Marine Carbon Sequestration. Frontiers in Marine Science 4.

Duarte, C.M., Middelburg, J.J. \& Caraco, N. (2005). Major role of marine vegetation on the oceanic carbon cycle. Biogeosciences 2, 1-8.

Gallagher, J.B. (2011). A song of the south: Evidence of an inter-decadal limit-cycles within a seagrass landscape, driven by a higher octave nutrient consonanace. A Paleorecontruction. In: Young C, Besenyei, L., Hooper, I., and Moreton-Jones, K. (ed) Landscape Ecology and Ecosystem Services. Unversity of Wolverhampton: ialeUK, pp193-197.

Gallagher, J.B. (2013). Natural and anthropogenic ecosystem regime variance within a tide-dominated estuary: A late Anthropocene palaeoreconstruction. Department of Zoology. University of Tasmania, 239pp.

Gray, V. (2007). Climate change 2007: The physical science basis summary for policymakers. Energy and Environment 18, 433-440.

Gullström, M., Lyimo, L.D., Dahl, M. et al. (2017). Blue carbon storage in tropical seagrass meadows relates to carbonate stock dynamics, plantsediment processes, and landscape context: Insights from the Western Indian Ocean. Ecosystems 1-16,

Habeeb, R.L. Johnson, C.R. Wotherspoon, S. et al. (2007). Optimal scales to observe habitat dynamics: A coral reef example. Ecological Applications 17, 641-647.
Hessen, D.O., Agren, G.I., Anderson, T.R. et al. (2004). Carbon, sequestration in ecosystems: The role of stoichiometry. Ecology 85, 1179. 1192.

Howard, J.L., Creed, J.C., Aguiar, M.V.P. et al. (2017). $\mathrm{CO}_{2}$ released by carbonate sediment production in some coastal areas may offset the benefits of seagrass "Blue Carbon" storage. Limnology and Oceanography

Hu, X.P. \& Burdige, D.J. (2008). Shallow marine carbonate dissolution and early diagenesis-Implications from an incubation study. Journal of Marine Research 66, 489-527.

Jiao, N., Gerhard, J., Herndl, D.A. et al. (2010). Microbial production of recalcitrant dissolved organic matter: long-term carbon storage in the global ocean. Nature Reviews Microbiology 8, 593.

Kondrashov, D. \& Ghil, M. (2006). Spatio-temporal filling of missing points in geophysical data sets. Nonlinear Processes in Geophysics 13 151-159.

Krause-Jensen, D. \& Duarte CM. (2016). Substantial role of macroalgae in marine carbon sequestration. Nature Geoscience 9, 737-742.

Luz, L.G., Carreira, R.S., Farias, C.O. et al. (2010). Trends in PAH and black carbon source and abundance in a tropical mangrove system and possible association with bioavailability. Organic Geochemistry 41, 11461155 .

Marba, N. \& Duarte, C.M. (1997). Interannual changes in seagrass (Posidonia oceanica). growth and environmental change in the Spanish Mediterranean littoral zone. Limnology and Oceanography 42, 800-810.

Martin, P., Sebastien, D., Gilles, T. et al. (2010). Long-term evolution (1988-2008) of Zostera spp. meadows in Arcachon Bay (Bay of Biscay). Estuarine Coastal and Shelf Science 87, 357-366.

Mazarrasa, I., Marbà, N., Lovelock, CE. et al. (2015). Seagrass meadows as a globally significant carbonate reservoir. Biogeosciences 12,4993 5003.

Middelburg, J.J. (1989). A simple rate model for organic matter decompostion in marine sediments. Geochimica et Cosmochimica Acta 53, 1577-1581.

National Research Council. (2000). Clean coastal waters Understanding and Reducing the Effects of Nutrient Pollution Committee on the Causes and Management of Coastal Eutrophication Ocean Studies Board and Water Science and Technology Board, Washington, D.C., National academy press.

Nellemann, C., Corcoran, E. Duarte, C.M. et al. (2009). Blue Carbon. A rapid response assessment. GRID-Arenda; United Nations Environment Programme.

Pendleton, L., Donato, D.C, Murray, B.C. et al. (2012). Estimating Global "Blue Carbon" Emissions from Conversion and Degradation of Vegetated Coastal Ecosystems. Plos one 7.

Siikamäki, J., Sanchirico, J.N., Jardine, S. et al. (2013). Blue Carbon: Coastal Ecosystems, Their Carbon Storage, and Potential for Reducing Emissions. Environment: Science and Policy for Sustainable Development 55, 14-29.

Smith, J.N. (2001). Why should we believe Pb-210 Sediment geochronologies? Journal of Environmental Radioactivity 55, 121-123.

Stenseth, N.C., Ottersen, G., Hurrell, J.W. et al. (2003). Studying climate effects on ecology through the use of climate indices: the North Atlantic Oscillation, El Nino Southern Oscillation and beyond. Proceedings of the Royal Society of London Series B-Biological Sciences 270, 2087-2096.

Yamakita, T., Watanabe, K. \&, Nakaoka, M. (2010). Asynchronous local dynamics contributes to stability of a seagrass bed in Tokyo Bay. Ecography $34,519-528$. 